\title{
New Lignan Isolated from Phyllanthus niruri Linn. Structure Elucidation by NMR Spectroscopy
}

\author{
Wan-Xing Wei, Xing-guo Gong, Omar Ishrud, and Yuan-Jiang Pan \\ Department of Chemistry, Zhejiang University, Hangzhou 310027, P.R. China \\ "College of Life Sciences, Zhejiang University, Hangzhou 310027, P.R. China \\ Received Jamary 28, 2002
}

Keywords : Phyllanthis nintri Lim, NMR Spectroscopy, Structure, Elucidation, Neonirtetralin.

Phyllanthts niruri linn was a well-known medicinal plant that grows in many countries, and was used as a medicine for the treatment of hepatitis disease in India. ${ }^{3}$ Many other studies on this plant showed that it has many bioactivities. ${ }^{\text {?-1? }}$ Many works had been done on the chemical compositions of this plant. ${ }^{13-16}$ The interesting biological activities of this plant prompted us to work on this specie. We report here the isolation and structure of a new compound by a combination of NMR techniques, including ${ }^{1} \mathrm{H}-{ }^{1} \mathrm{H}$ COSY, ${ }^{13} \mathrm{C}-{ }^{1} \mathrm{H}$ COSY, DEPT, HMBC and NOESY.

Neonirtetralin (1) has a molecular formula as $\mathrm{C}_{24} \mathrm{H}_{30} \mathrm{O}_{7}$ that was determined by EI-MS and elemental analysis. The ${ }^{l} \mathrm{H},{ }^{13} \mathrm{C}$, and DEPT NMR spectra of $\mathbf{1}$ (see Table 1) showed the signals for five methyl groups, four methylene groups, seven methine groups (four aromatic methine groups among

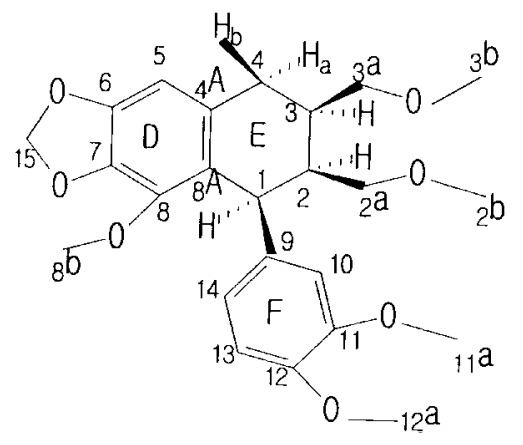

Figure 1. Contiguration of compound (1).

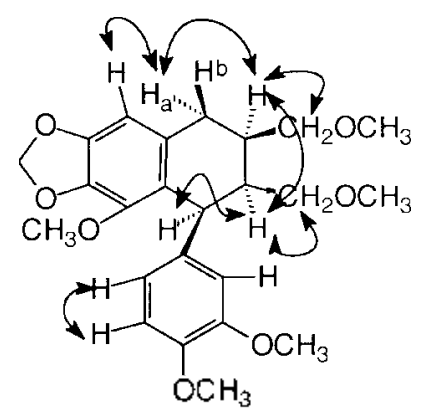

Figure 2. Principal NOESY correlations in $\mathbf{1 .}$
Table 1. ${ }^{1} \mathrm{H},{ }^{13} \mathrm{C}$ chemical shift and principal $\mathrm{HMBC}$ correlations of (1) in $\mathrm{CDCl}_{3}$

\begin{tabular}{ccrl}
\hline Atom & ${ }^{1} \mathrm{H}$ (Multiplicity) & \multicolumn{1}{c}{${ }^{13} \mathrm{C}$} & \multicolumn{1}{c}{ HMBC (Carbon) } \\
\hline $\mathrm{l}$ & $4.26(1 \mathrm{H})$ & 41.64 & $3,2,2 \mathrm{a}, 10,14,8 \mathrm{~A}, 4 \mathrm{a}, 9,8$ \\
2 & $1.98(1 \mathrm{H})$ & 45.56 & $4,3,1,3 \mathrm{a}, 2 \mathrm{a}, 9,8 \mathrm{a}$ \\
3 & $1.81(1 \mathrm{H})$ & 37.16 & - \\
$4 \mathrm{a}$ & $2.69(1 \mathrm{H})$ & 33.61 & $3,2,3 \mathrm{a}, 5,8 \mathrm{a}, 4 \mathrm{~A}, 6,8,7$ \\
$4 \mathrm{~b}$ & $2.55(1 \mathrm{H})$ & 33.61 & $3,2,3 \mathrm{a}, 5,8 \mathrm{a}, 4 \mathrm{~A}, 6,8$, \\
5 & $6.37(1 \mathrm{H})$ & 103.12 & $4,8 \mathrm{a}, 6,8,7$ \\
6 & - & 135.79 & $4,8 \mathrm{a}, 6,8,7$ \\
7 & - & 147.64 & - \\
8 & - & 142.08 & - \\
$2 \mathrm{a}$ & $3.24(2 \mathrm{H})$ & 73.64 & 2,4 \\
$3 \mathrm{a}$ & $3.24(2 \mathrm{H})$ & 76.24 & 3 \\
$2 \mathrm{~b}$ & $3.31(3 \mathrm{H})$ & 59.14 & $2 \mathrm{a}$ \\
$3 \mathrm{~b}$ & $3.26(3 \mathrm{H})$ & 59.10 & $3 \mathrm{a}$ \\
$4 \mathrm{~A}$ & - & 132.14 & - \\
$8 \mathrm{~A}$ & - & 125.02 & - \\
$8 \mathrm{~b}$ & $3.45(3 \mathrm{H})$ & 59.20 & 8 \\
15 & $5.82(2 \mathrm{H})$ & 101.35 & 6,7 \\
9 & - & 139.95 & - \\
10 & $6.68(1 \mathrm{H})$ & 112.10 & $1,14,9,11,12$ \\
11 & - & 148.64 & - \\
$11 \mathrm{a}$ & $3.79(3 \mathrm{H})$ & 56.11 & 11 \\
$12 \mathrm{a}$ & $3.79(3 \mathrm{H})$ & 56.03 & 12 \\
12 & - & 147.02 & - \\
13 & $6.68(1 \mathrm{H})$ & 110.88 & $1,14,9,11,12$ \\
14 & $6.53(1 \mathrm{H})$ & 120.10 & $1,13,10,11,12$ \\
\hline
\end{tabular}

Multiplicity was provided by DEPT ( $90^{\circ}$ and $\left.135^{3}\right)$ spectra

these seven methine groups) and eight quaternary carbons.

Compound (1) is a stereo-isomer of nirtetralin. ${ }^{13}$ Their NMR data and other properties are different. When sprayed with $5 \%$ sulfuric acid in methanol on a silica gel plate and then heated, compound (1) had a blue black spot and nirtetralin formed a violet spot. ${ }^{13}$

In ${ }^{1} \mathrm{H}-{ }^{1} \mathrm{H}$ COSY spectrum, the proton signal at $\delta 4.26 \mathrm{ppm}$ $(\mathrm{H}-1)$ and the proton signal at $\delta 1.98 \mathrm{ppm}(\mathrm{H}-2), \mathrm{H}-2$ and the proton signal at $\delta 1.81 \mathrm{ppm}(\mathrm{H}-3), \mathrm{H}-3$ and the proton signal 
at $\delta 2.69 \mathrm{ppm}(\mathrm{H}-4 \mathrm{a})$ and $\delta 2.55 \mathrm{ppm}(\mathrm{H}-4 \mathrm{~b})$ had crosspeaks. Meanwhile $\mathrm{H}-2$ and the proton signal at $\delta 3.24 \mathrm{ppm}$ (H-2a), H-3 and the proton signal at $\delta 3.24 \mathrm{ppm}(\mathrm{H}-3 \mathrm{a})$, the proton signal at $\delta 6.68 \mathrm{ppm}(\mathrm{H}-13)$ and the proton signal at $\delta$ $6.53 \mathrm{ppm}(\mathrm{H}-14)$ had cross-peaks. Those cross-peaks revealed the facts that $\mathrm{H}-1$ was proximate to $\mathrm{H}-2, \mathrm{H}-2$ was proximate to $\mathrm{H}-3, \mathrm{H}-3$ was proximate to $\mathrm{H}-4$, and $\mathrm{H}-2$ and $\mathrm{H}-3$ were proximate to $\mathrm{H}-2 \mathrm{a}$ and $\mathrm{H}-3 \mathrm{a}$, respectively. $\mathrm{H}-13$ was proximate to $\mathrm{H}-14$. The $\mathrm{HMBC}$ data supported the structure elucidation of compound (1). The proton signal at $\delta$ $4.26 \mathrm{ppm}(\mathrm{d}, J=6.28)$ and carbon signal at $\delta 41.64 \mathrm{ppm}$ were assigned to $\mathrm{H}-1$ and $\mathrm{C}-1$, respectively. The carbon signal at $\delta 37.16 \mathrm{ppm}$ correlated with the proton signal at $\delta$ $4.26 \mathrm{ppm}$ (d, $J=6.28 \mathrm{~Hz}$ ) which showed cross-peaks with the carbon signals at $\delta 45.56 \mathrm{ppm}(\mathrm{C}-2), \delta 73.64 \mathrm{ppm}(\mathrm{C}$ $2 \mathrm{a}), \delta 112.10 \mathrm{ppm}(\mathrm{C}-10), \delta 120.10 \mathrm{ppm}(\mathrm{C}-14), \delta 125.02$ ppm (C-8a), $\delta 132.14$ ppm (C-4A), $\delta 139.95$ ppm (C-9) and $\delta 142.08 \mathrm{ppm}(\mathrm{C}-8)$. These indicated that ring $\mathbf{F}$ was located at the $\mathrm{C}-1$ position. The carbon signal at $\delta 135.79 \mathrm{ppm}(\mathrm{C}-6)$ correlated with the proton signal at $\delta 5.82 \mathrm{ppm}(\mathrm{H}-15)$ which showed cross-peak with the carbon signal at $\delta 147.64 \mathrm{ppm}$ (C-7). Proton signal at $\delta 6.37 \mathrm{ppm}(\mathrm{H}-5)$ had cross-peaks with carbon signals at $\delta 33.61 \mathrm{ppm}(\mathrm{C}-4), \delta 135.79 \mathrm{ppm}(\mathrm{C}$ 6), $\delta 147.64 \mathrm{ppm}(\mathrm{C}-7)$, and $\delta 125.02 \mathrm{ppm}(\mathrm{C}-8 \mathrm{~A}), \delta 142.08$ ppm (C-8). These evidences indicated that the methenedioxy group was connected to $\mathrm{C}-6$ and $\mathrm{C}-7$. Meanwhile the HMBC correlations from the carbon signal at $\delta 73.64 \mathrm{ppm}(\mathrm{C}-2 \mathrm{a})$ to the proton signal at $\delta 1.98 \mathrm{ppm}(1 \mathrm{H}, \mathrm{m}, J=4.80 \mathrm{~Hz}, \mathrm{H}-2)$, the carbon signal at $\delta 76.24 \mathrm{ppm}(\mathrm{C}-3 \mathrm{a})$ to the proton signal at $\delta 1.81 \mathrm{ppm}(1 \mathrm{H}, \mathrm{m}, J=4.45 \mathrm{~Hz}, \mathrm{H}-3)$, the carbon signal at $\delta 59.10 \mathrm{ppm}(\mathrm{C}-3 \mathrm{~b})$ to the proton signal at $3.24 \mathrm{ppm}(2 \mathrm{H}, \mathrm{m}$, $\mathrm{H}-3 \mathrm{a})$, the carbon signal at $\delta 59.14 \mathrm{ppm}(\mathrm{C}-2 \mathrm{~b})$ to the proton signal at $\delta 3.24 \mathrm{ppm}(2 \mathrm{H}, \mathrm{m}, \mathrm{H}-2 \mathrm{a})$, and their DEPT spectrum indicated that $\mathrm{C}-2 \mathrm{a}$ and $\mathrm{C}-3 \mathrm{a}$ were methylene group respectively and these two carbons connectted to methoxy group respectively. HMBC spectrum also showed that proton signal at $\delta 3.79 \mathrm{ppm}(3 \mathrm{H}, \mathrm{s}, \mathrm{H}-11 \mathrm{a})$ correlated to the carbon signal at $\delta 148.64 \mathrm{ppm}(\mathrm{C}-11)$, the proton signal at $\delta 3.79 \mathrm{ppm}(3 \mathrm{H}, \mathrm{s}, \mathrm{H}-12 \mathrm{a})$ correlated to the carbon signal at $\delta 147.0 \mathrm{ppm}(\mathrm{C}-12)$, and the proton signal at $\delta 3.45 \mathrm{ppm}$ ( $3 \mathrm{H}, \mathrm{s}, \mathrm{H}-8 \mathrm{~b}$ ) correlated to the carbon signal at $\delta 142.0 \mathrm{ppm}$ (C-8). These evidences and DEPT spectrum revealed that $\mathrm{C}$ $11, \mathrm{C}-12$ and $\mathrm{C}-8$ connected with methoxy group respectively. The $\mathrm{HMBC}$ correlations of proton signal at $\delta 6.53$ ppm $(1 \mathrm{H}, \mathrm{m}, J=6.95,1.35 \mathrm{~Hz}, \mathrm{H}-14)$ to the carbon signals at $\delta 41.64 \mathrm{ppm}(\mathrm{C}-1), \delta 110.88 \mathrm{ppm}(\mathrm{C}-13), \delta 112.10 \mathrm{ppm}$ $(\mathrm{C}-10)$ and the proton signal at $\delta 6.68 \mathrm{ppm}(1 \mathrm{H}, \mathrm{d}, J=1.35$ $\mathrm{Hz}, \mathrm{H}-10$ ) to $\delta 41.46 \mathrm{ppm}(\mathrm{C}-1), \delta 139.95 \mathrm{ppm}$ (C-9), $\delta$ $148.64 \mathrm{ppm}(\mathrm{C}-11), \delta 147.02 \mathrm{ppm}(\mathrm{C}-12), \delta 120.10 \mathrm{ppm}(\mathrm{C}-$ 14), and ${ }^{1} \mathrm{H}-{ }^{1} \mathrm{H}$ COSY of $\mathrm{H}-14, \mathrm{H}-13$ showed that $\mathrm{H}-13$ and $\mathrm{H}-14$ located at ortho position, $\mathrm{H}-14$ and $\mathrm{H}-10$ at meta position in ring $\mathbf{F}$. The coupling constants of $\mathrm{H}-13$ and $\mathrm{H}-14$ $(J=6.95 \mathrm{~Hz})$ and of $\mathrm{H}-14$ and $\mathrm{H}-10(J=1.35 \mathrm{~Hz})$ support the proton locations at the ring $\mathbf{F}$. The correlation of proton signal at $\delta 6.37 \mathrm{ppm}(\mathrm{H}-5)$ with carbon signal at $\delta 33.61 \mathrm{ppm}$ $(\mathrm{C}-4)$ in HMBC, and the NOESY evidences of protons signals at $\delta 6.37 \mathrm{ppm}(\mathrm{H}-5)$ and $\delta 2.69 \mathrm{ppm}$ (4a) confirmed that the carbon signal at $\delta 33.61 \mathrm{ppm}$ connected to $\mathrm{C}-5$ at ring $\mathrm{C}$. Meanwhile the correlations of the proton signal at $\delta$ 4.26 ppm (H-1) with the carbon signal at $\delta 142.08$ ppm $(\mathrm{C}-$ 8), $\delta 125.02$ ppm (C- $8 \mathrm{~A})$, and the proton signal at $\delta 3.45$ ppm ( $\mathrm{H}-8)$ with the carbon signal at $\delta 142.08$ ppm (C-8) in HMBC indicated that the carbon signal at $\delta 41.64 \mathrm{ppm}(\mathrm{C}$ 1), which connected with the proton ( $\mathrm{H}-1)$, connected to the aromatic carbon signal at $\delta 125 \mathrm{ppm}(\mathrm{C}-8 \mathrm{~A})$.

The NOESY of compound (1) confirmed the structure (see Fig. 1). Cross-peaks of proton signal at $\delta 4.26 \mathrm{ppm}(\mathrm{H}-$ 1) with the proton signal at $\delta 1.98 \mathrm{ppm}(\mathrm{H}-2)$, the proton signal at $\delta 1.98 \mathrm{ppm}(\mathrm{H}-2)$ with the proton signal at $\delta 1.81$ ppm (H-3), the proton signal at $\delta 1.81 \mathrm{ppm}(\mathrm{H}-3)$ with the proton signals at $\delta 2.69$ ppm $(\mathrm{H}-4 \mathrm{a})$ and the proton signals at $\delta 2.69$ ppm (H-4a) with the proton signals at $\delta 6.37 \mathrm{ppm}$ ( $\mathrm{H}-$ 5) appeared in the NOESY spectrum. Those NOESY spectrum evidences showed that $\mathrm{H}-1$ and $\mathrm{H}-2, \mathrm{H}-2$ and $\mathrm{H}-3$, $\mathrm{H}-3$ and $\mathrm{H}-4 \mathrm{a}, \mathrm{H}-4 \mathrm{a}$ and $\mathrm{H}-5$ were proximate in space. $\mathrm{H}-5$ was in the plane of benzene ring, and it had NOE with $\mathrm{H}-4 \mathrm{a}$. It means that $\mathrm{H}-4 \mathrm{a}$ was at the plane, which connected to the benzene ring. The protons at 1, 2,3 positions were linked to relative carbons in equator orientation. If one of $\mathrm{H}-1, \mathrm{H}-2$, $\mathrm{H}-3$ was at the axial orientation just as in nirtetralin, the three hydrogen would not have NOE each other. It was deduced that $\mathrm{H}-1, \mathrm{H}-2, \mathrm{H}-3, \mathrm{H}-4$ linked to correlative carbons respectively at the equator orientation. The NOESY evidence of $\mathrm{H}-4$ and the proton signal at $\delta 6.37$ ppm (H-5) revealed the fact that the another only one proton had to locate at 5 position in ring $C$. The coupling constants of these protons supported the fact. The coupling constant between $\mathrm{H}-1$ and $\mathrm{H}-2$ was $6.18 \mathrm{~Hz}$, the coupling constants between $\mathrm{H}-2$ and $\mathrm{H}-3, \mathrm{H}-3$ and $\mathrm{H}-4$ were $4.25 \mathrm{~Hz}$ and $4.51 \mathrm{~Hz}$, respectively. On the basis of above evidences, the three protons at $\mathrm{C}-1, \mathrm{C}$ $2, \mathrm{C}-3$ were assigned to be in the $\beta, \beta, \beta$ orientation. Therefore, neonirtetralin (1) was elucidated to be $(1 \beta, 2 \beta$, $3 \beta$ )-2,3-dimethoxymethyl-6,7-metheneioxy-8-methoxy-1(11,12-dimehtoxyphenyl) naphthanlene. Structure of neonirtetralin, and its configuration was showed in Figure 1.

Compound (2) was elucidated as which spectral data was in good agreement with those of previous reported phyllanthin ${ }^{14}$ and compound (3) was elucidated as hypophylanthin on the basis of those of reported compound from literature. ${ }^{15,16}$

\section{Experimental Section}

General methods. ${ }^{1} \mathrm{H}-\mathrm{NMR}(500 \mathrm{MHz})$ and ${ }^{17} \mathrm{C}-\mathrm{NMR}$ $(125 \mathrm{MHz})$ were recorded on a Bruker AM-500 spectrometer. Sample dissolved in $\mathrm{CDCl}_{3}$ for NMR studies. Chemical shifts were reported in ppm. Coupling constants ( $J$-Values) were given in Hertz (Hz). EIMS spectrum was recorded using HP5989B MASS spectrometer. Elementary analysis was performed on a PE2400 CHN elemental analyzer.

Plant material: The plant material was collected from Longan county, Guangxi province at August 2001 and was identified as Phllanthus nimi L. A voucher specimen was 
kept in the botany Department of Zhejiang University.

Isolation and purification. The air dried P. nirtwi $(3.5 \mathrm{~kg})$ was extracted with ethanol, with constant mechanical stirring: this procedure was repeated until no further extract bud was obtained. The combined extracts were filtered while warm through glass wool, concentrated. The residue $(120 \mathrm{~g})$ was extracted successively with petroleum ether and ethyl acetate. The mixture of petroleum ether extracts and ethyl acetate extracts was centrifuged, and concentrated to dryness and got $15 \mathrm{~g}$ residue. Chromatography of the $15 \mathrm{~g}$ residue was applied in silica gel $(40-60 \mu \mathrm{m})$ column using the solvent system of petroleum ether and ethyl acetate as eluent. The chromatography different polarities systems demonstrated after $15 \times 500 \mathrm{~mL}$ eluent was applied. The fraction obtained at a ratio of $20: 3$ of petroleum ether and ethyl acetate (volume ratio) gave $250 \mathrm{mg}$ liquid residue and, was purified by vacuum liquid chromatography and preparative TLC to give $78 \mathrm{mg}$ of pure compound (1). The fraction obtained at a ratio of $20: 4$ of petroleum ether and ethyl acetate gave a solid residue $(450 \mathrm{mg})$. This solid residue was crystallized repeatedly in methanol to give $250 \mathrm{mg}$ compound (2). The fraction obtained at a ratio of $3: 1$ of petroleum ether and ethyl acetate gave solid residue ( $1.35 \mathrm{~g}$ ). This $1.35 \mathrm{~g}$ residue was crystallized in methanol repeatedly to give $660 \mathrm{mg}$ compound (3).

Neonirtetralin: colorless oil. EIMS m/z: 430, and elemental analysis $\mathrm{C} 67.0 \% \mathrm{H} 7.0 \%$ (calcd. $430.49,66.96 \mathrm{C} \%, \mathrm{H} 7.02 \%$ ) for $\mathrm{C}_{24} \mathrm{H}_{30} \mathrm{O}_{7},{ }^{1} \mathrm{H},{ }^{13} \mathrm{C}$, DEPT NMR spectral data and principal HMBC are listed in Table 1. Most of NOESY correlations are in Figure 2.
Acknowledgment. This work was supported by the National Science Foundation of China (No. 29805002) and Science Foundation of Zhejiang province (Rc00042).

\section{References}

1. Thyagarajan, S. P. et al. The Lancet. 1988. 1.764

2. Wan. L.; Jiang. Z.-Z.; Huang. B.-Z. Xinzhongyi. 1997, 29(5), 39 (China).

3. Ogata, T.: Higuchi, H. et al AlDS Res. Hum. Retrovirtises. 1992. $8(11), 1937$.

4. Calixto, J. B.: Santos, R. S. A.; Paulino, N. Cient. Cult. 1997, 49(5/6). 422 .

5. Joy. K. L.; Kuttan. R. J. Clin. Biochem. Nttr: 1998, 24(3). 133.

6. Ott. M.; Thyagarajan, S. P.; Gupta. S. Eul: J. Clin. Inest. 1997. $27(1), 908$.

7. Lee, C. D.; Ott, M.; Thyagarajan, S. P. Eur J. Clin. Invst. 1996 , 26(12), 1069-76.

8. Syamasundar. K. V.; Bikram. S.; Thakur. R. S. J. Ethophamacol. $1985,14(1) .41$

9. Hussaain, R. A.; Dickey, J. K.; Rosser, M. P. et al. J. Nat. Prod. $1995,58(10), 1515$.

10. Polya, G. M.; Wang, B. H. et al Phytochemisty 1995, $38(2), 307$.

11. Eur: Pat. Appl. EP.199. 429, 1986.

12. Rajeshkumar. N. V.; Kuttan, R. Jotmal of Enthopharmacology 2000, 73. 215.

13. Anjanteyulu. A. S. R.; Rao, K. T. et al. Tetrahedron 1973, 29(10), 1291.

14. Row, L. R.: Srinivasulu, C. Tetrahedron. 1966, 22(8), 2899.

15. Ward, R. S.: Satyanarayan, P. et al. Tetrahedron Lett. 1979, 32 , 3043.

16. Somanabandhu. A.; Nitayangkura. S.; Mahidol. C. I. Nat. Prod. $1993,56(2) .261$. 